\title{
EDITORIAL \\ Developing e-learning experiences and practices: the importance of context
}

This is my last editorial before I step down from the $A L T-J$ editorial team. Rhona Sharpe and Frances Bell, will form the new $A L T-J$ editorial team and I wish them the best of luck in developing the direction of $A L T-J$ in the future. I would also like to thank the rest of outgoing editorial team, the $A L T-J$ editorial board, the reviewers and authors that I have worked with over the last six issues of $A L T-J$, who each in their way has contributed to furthering our knowledge and understanding of the relationship between technology and learning.

Before I step down as editor it seems appropriate for me to look back on the field of e-learning and reflect on the progress and developments that have been made in the time since I took up the post of $A L T-J$ editor back in 2001. The last time I undertook such a reflective exercise was in 2003, when I edited a book that aimed to celebrate the tenth anniversary of the Association for Learning Technology through a review of the impact of learning technology on tertiary education. Interestingly, three of the contributors to that review are authors of papers in this issue (Boyle, Deepwell and Oliver). I introduced the review by arguing that the years 1993-2003 had not been particularly characterized by revolutionary or dramatic developments and that the future would be characterized by gradual rather than radical change (Seale 2003). It might be interesting, therefore, to consider whether the articles in this issue of $A L T-J$ are reporting radical or dramatic developments in e-learning policy, research or practice.

In this issue we have four articles. Deepwell and Malik present a case study of learner experiences and explore three emerging aspects of the learning experience: student expectations of the technology, lecturers engagement with technology and how technology might support processes of transition in higher education. San Diego et al. describe the development of a prototype for a pedagogy planning tool that can scaffold the process of learning design for teachers and lecturers. Wong, Shephard and Phillips apply the cathedral and bazaar analogy to the development of repositories, while Wali, Winters and Oliver use activity theory to develop theorized conceptions of mobile learning.

Is there anything radical or new in these papers? In one sense no there isn't. There have been numerous studies over the years that have reported learner responses and satisfaction regarding the use of learning technologies (see, for example, Slaouti 2001). Readers of ALT-J would also be able to trace the origins of learning design back to articles that discussed instructional systems such as REAL (Grabinger and Dunlap 1995). The growth of learning object research in the early part of this millennium went hand in hand with the development of repositories (see, for example, Currier et al. 2004; Lukusiak et al. 2005) and activity theory has already been used as a tool to conceptualize particular aspects of e-learning (see, for example, Waycott 2002).

So, what do the articles in this issue offer us which adds something new to our understanding of e-learning and perhaps has the potential to significantly progress practice and experience? Collectively, I believe these articles contribute to the idea that we need to understand the contexts in which learners, teachers and institutions are trying to use e-learning. By seeking to understand contexts we may better understand the relationship between learning and technology. For example, in my own field of accessibility I have argued for a contextualized model of accessibility that takes into account the stakeholders, the context (drivers and mediators) and how the 
relationship between stakeholders and the context influences the responses that stakeholders make and the practices that develop (Seale 2006).

For the students in Deepwell and Maliks' study context becomes important in that the results suggest that students would like more academic guidance from academic tutors on what and how to use technology to learn more independently. The implication is that at key transitional points students need guidance to be contextualized by a subject expert (course tutor), as opposed to a process expert (e.g. librarian). San Diego et al. argue that the modelling of pedagogy and learning design needs to be contextualized for lecturers, where the context could range from learning outcomes and activities to modules and programmes. Wong, Shephard and Phillips argue that community engagement with repositories needs to be understood within the context of the preexisiting traditions and values of teaching and learning within an institution and a discipline as well as the teachers' mindset regarding innovation. Wali, Winters and Oliver argue that future studies of mobile learning need to look at learning activities that take place across contexts (represented as both physical and social), placing more emphasis on the relationship between learning activities and social contexts.

In each article a different stakeholder is represented: from student to lecturer to a community as a whole. The contexts in which these stakeholders operate also vary. For students the context is key transitional periods, such as the transition between school and university. For lecturers the context is the particular level for which learning is being designed, while for users of mobile learning the experience of use has to be understood in multiple virtual and physical contexts. For communities the development of repositories needs to be understood in the context of histories, cultures and traditions. The relationship between stakeholders and these contexts may influence the response that stakeholders make. For example, for the students in Deepwell and Maliks' study the response is a reliance on lecturing staff.

In 2003 Oliver argued:

To do justice to our field, we need to balance our fascination with the new and strange (such as mobile computing) alongside the overly familiar. (Oliver 2003, 159)

For me, the overly familiar or taken for granted is the context in which technology is used to support or enhance learning. What each article in this issue of $A L T-J$ offers us is an important reminder of the importance and influence of context. Understanding the relationship between learning and technology is all about understanding context.

Jane K. Seale

University of Southampton

\section{References}

Currier, S., J. Barton, R. O'Bierne, and B. Ryan. 2004. Quality assurance for digital learning object repositories: Issues for the metadata creation process. ALT-J 12, no. 1: 5-20.

Grabinger, S. and J. Dunlap. 1995. Rich environments for active learning: a definition. ALT-J 3, no. 2: $5-34$.

Lukasiak, J., S. Agostinho, S. Bennett, B. Harper, L. Lockyer and B. Powley. 2005. Learning object and learning designs: An integrated system for reusable adaptive and shareable learning content. ALT-J 13, no. 2: 151-70.

Oliver, M. 2003. Looking backwards, looking forwards: An overview, some conclusions and an agenda. In Learning technology in transition: From individual enthusiasm to institutional implementation, ed. J.K. Seale, 147-60. Abingdon, UK: Swets and Zeitlinger.

Seale, J.K., ed. 2003. Learning technology in transition: From individual enthusiasm to institutional implementation. Abingdon, UK: Swets and Zeitlinger.

Seale, J. 2006. E-learning and disability in higher education: accessibility research and practice. London: Routledge. 
Slaouti, D. 2001. Student 'voices' and course development: Reading the signs on a distance course in educational technology. ALT-J 9, no. 1: 62-72.

Waycott, J. 2002. Reading with new tools: An evaluation of personal digital assistants as tools for reading course materials. $A L T-J 10$, no. 2: 38-50. 